\title{
QUINOLONE-RESISTANT ESCHERICHIA COLI IN POULTRY FARMING
}

\author{
Kristýna Hricová1, Magdaléna Röderová1, Vendula Pudová1, Vojtěch Hanulík', Dana Halová3, Pavla Julínková3, \\ Monika Dolejská3, Ivo Papoušek ${ }^{3}$, Jan Bardoň ${ }^{1,2}$ \\ ${ }^{1}$ Department of Microbiology, Faculty of Medicine and Dentistry, Palacký University Olomouc, Olomouc, Czech Republic \\ ${ }^{2}$ State Veterinary Institute, Olomouc, Czech Republic \\ ${ }^{3}$ Department of Biology and Wildlife Diseases, Faculty of Veterinary Hygiene and Ecology, University of Veterinary and Pharmaceutical \\ Sciences, Brno, Czech Republic
}

\begin{abstract}
SUMMARY
Increasing bacterial resistance to quinolone antibiotics is apparent in both humans and animals. For humans, a potential source of resistant bacteria may be animals or their products entering the human food chain, for example poultry. Between July 2013 and September 2014, samples were collected and analyzed in the Moravian regions of the Czech Republic to isolate the bacterium Escherichia coli. As a result, 212 E. coli isolates were obtained comprising 126 environmental isolates from poultry houses and 86 isolates from cloacal swabs from market-weight turkeys. Subsequently, the $E$. coli isolates were tested for susceptibility to selected antibiotics. Resistance of the poultry isolates to quinolones ranged from $53 \%$ to $73 \%$. Additionally, the presence of plasmid-mediated resistance genes was studied. The genes were confirmed in 58\% of the tested strains. The data on resistance of isolates from poultry were compared with results of resistance tests in human isolates obtained in the same regions. The high levels of resistance determined by both phenotyping and genotyping methods and reported in the present study confirm the fact that the use of fluoroquinolones in poultry should be closely monitored.
\end{abstract}

Key words: Escherichia coli, antibiotic resistance, poultry, quinolones, plasmids

Address for correspondence: K. Hricová, Department of Microbiology, Faculty of Medicine and Dentistry, Palacký University Olomouc, Hněvotínská 3, 77515 Olomouc, Czech Republic. E-mail: hricova.k@email.cz

https://doi.org/10.21101/cejph.a4328

\section{INTRODUCTION}

Escherichia coli is a common commensal bacteria of humans and animals that, under certain circumstances, may become a troublesome pathogen causing serious diseases. In humans, it most frequently causes gastrointestinal diseases and urinary tract infections. Severe conditions include extraintestinal infections and complications caused by toxins produced by verotoxigenic E. coli $(1,2)$. In animals, E. coli may cause urinary and gastrointestinal tract infections, septicaemia and respiratory tract infections $(3,4)$.

Antibiotic agents that could be used to treat infections caused by this bacterium include fluoroquinolones, newer quinolones containing a fluorine atom. In veterinary medicine a large proportion of these antimicrobials belong to a group of drugs with the so-called restricted indication. It means that they may be used only if the causative bacterial agent is identified and tested for susceptibility to various antibiotics, with the results clearly showing that for the particular purpose no other suitable agent without such a restriction is available $(5,6)$.

Quinolone antibiotics with bactericidal effects were introduced in the form of nalidixic acid in the 1960s. This fully synthetic agent was discovered as a byproduct of research on antimalarial drugs. The first generation of quinolones (e.g. nalidixic acid or oxolinic acid) was used in humans to treat uncomplicated urinary tract infections caused mainly by E. coli (7). The addition of a fluorine atom and other components to the basic quinolone structure in the 1980s increased the effectiveness and range of action of these antimicrobials to involve other microorganisms (8). The first original veterinary fluorinated quinolone was enrofloxacin, introduced into practice in the Czech Republic in $1992(7,9)$.

Quinolones interfere with the synthesis of bacterial DNA by inhibiting bacteria enzymes of the topoisomerase class, namely DNA gyrase (topoisomerase II) in Gram-negative bacteria and topoisomerase IV in Gram-positive microorganisms. These enzymes modify the DNA double helix in the course of replication. DNA gyrase and topoisomerase IV are heterotetramers containing two subunits A and B. They are encoded by the genes gyrA and gyrB (in DNA gyrase) and parC and parE (in topoisomerase IV) $(10,11)$. The development of bacterial resistance to quinolone antibiotics is a multifactorial process of both chromosomal and plasmid origin (12).

The main mechanism of chromosomal resistance leads to a change in the structure of the target site (topoisomerase II and/or IV) at which the antibiotic acts because of a point mutation. Most frequently, the target enzymes are changed close to the active site and/or their affinity to the antibiotic is reduced. Mutations leading to quinolone resistance most frequently occur in the gene gyrA, namely in the quinolone resistance-determining region. At a chromosomal level, the development of resistance may be 
supported by reduced expression of outer membrane proteins or overexpression of efflux pumps $(3,10)$.

Horizontal transfer of resistance genes has also been confirmed, which is mediated by plasmids. Plasmid-mediated quinolone resistance (PMQR) genes contribute to quinolone resistance and the effect of their combination with other resistance mechanisms has been little studied (12). Since 1998, three basic mechanisms of plasmid-mediated resistance have been described. These include $Q n r$ peptides able to protect topoisomerases II and IV; substances able to modify, and thus inactivate, quinolones such as a variant of aminoglycoside acetyltransferase (Aac(6 )Ib) referred to as Aac(6 )-Ib-cr; and efflux pumps of the major facilitator superfamily such as the QepA efflux pump $(13,14)$.

High levels of resistance to quinolone antibiotics in poultry in the Czech Republic were reported, for instance, by Skočková et al. in 2015 (15). The authors studied resistance to selected antibiotics in samples collected from fresh meat (pork, poultry, beef, and venison) bought at retail store. The highest rates of resistance to all tested antibiotics were detected in poultry samples; the highest resistance levels were observed for quinolone antibiotics (nalidixic acid, 55\%; and ciprofloxacin, 38\%) and ampicillin (55\%) of the beta-lactam family. The 2012 European Food Safety Authority annual report (16) on antimicrobial resistance in indicator bacteria from humans, animals and foods in EU member states analyzed data on resistance of the above bacteria including E. coli to selected antibiotics. For poultry ( $\mathrm{Gal}-$ lus gallus), resistance to ciprofloxacin was detected in $52 \%$ of the tested E. coli strains, the highest level among all antibiotics included in the analysis.

An increase in bacterial resistance to fluoroquinolones is also apparent in the human population. Data from the European Antimicrobial Resistance Surveillance Network (EARS-Net) (17) showed that in $20018 \%$ of E. coli strains were resistant to fluoroquinolones in the Czech Republic. Over the following 12 years, the level of resistance increased to $22 \%$ in 2013 (17). The EARS-Net database maps and data from 2013 suggest that in more than a half of the participating European countries (e.g. France, Germany or Scandinavian countries) from $10 \%$ to $25 \%$ of human $E$. coli isolates were resistant to fluoroquinolones. In the remaining countries (e.g. Poland, Spain or Italy) the rates were higher ranging from $25 \%$ to $50 \%$. Data from the University Hospital Olomouc obtained in 2013-2014 showed levels of E. coli resistance to quinolone antibiotics that were lower than the mean European levels in 2013. The E. coli resistance was 13\% for ciprofloxacin and $16 \%$ for ofloxacin; the highest resistance level (20\%) was observed in oxolinic acid (data not published).

Low levels of plasmid-mediated resistance were reported in a 2011 comprehensive study by Veldman et al. (18) summarizing data from screening of databases in 13 European countries (including the Czech Republic) over a period of 1994-2009. However, the numbers of isolates included in the study varied considerably between the countries (e.g. 536 and 24,526 E. coli isolates in the Czech Republic and Denmark, respectively). The samples for isolation of $E$. coli were collected from different sources (animals, humans, foods, or the environment). In all $E$. coli isolates, only $q n r B$ and $q n r S$ genes were identified. No $q n r A$, qnrD or aac(6 )$1 \mathrm{~b}$-cr genes were detected. There were no positive isolates among samples from the Czech Republic. However, significantly higher numbers of $q n r B$ and $q n r S$ genes were observed in Salmonella enterica isolates. All of the above five genes were present in this bacterial species.

The prevalence of PMQR genes in humans in the Czech Republic was studied by Husičková et al. in 2012 (19). This was the first study aimed at detecting $q n r$ genes in clinical isolates in the Czech Republic. In clinical samples collected from University Hospital Olomouc samples, the presence of $q n r$ genes was detected in 56 out of 100 extended-spectrum beta-lactamase (ESBL)-positive Klebsiella pneumoniae isolates; in all cases, qnrB genes were identified.

Studies of clinical isolates from European countries (Norway, Sweden, France, Spain) often reported lower frequency of $q n r$ genes than $a a c\left(6^{\prime}\right)-1 b-c r$. While $q n r$ genes do not exceed $10 \%$, the prevalence of the $a a c\left(6^{\circ}\right)-1 b$ - $c r$ gene ranges from $16 \%$ to $52 \%$. Generally, higher rates of the two genes are observed in ESBL-positive strains (20-22).

\section{MATERIALS AND METHODS}

Over the years 2013 and 2014, samples for detection of E. coli were collected from two sources - environmental samples from poultry houses (broilers Gallus gallus) and cloacal swabs from market-weight turkeys (Meleagris gallopavo f. domestica). The samples were obtained in the Olomouc and South Moravia Regions. On poultry farms, environmental samples were taken from bedding using gauze shoe covers worn by a worker who walked through a poultry house. In the laboratory, the covers were put in peptone water, shaken and incubated aerobically for 24 hours at $37^{\circ} \mathrm{C}$. Subsequently, the peptone water was inoculated onto MacConkey agar with ciprofloxacin at a concentration of 0.05 $\mathrm{mg} / \mathrm{L}$ of the medium (Trios, Czech Republic) which was incubated aerobically for 24 hours at $37^{\circ} \mathrm{C}$.

Turkey cloacal swabs were collected at slaughterhouses in vivo prior slaughter using swabs with culture medium (Amies transport medium with activated charcoal; Trios). After delivery to the laboratory, the swabs were directly inoculated onto MacConkey agar with ciprofloxacin at a concentration of $0.05 \mathrm{mg} / \mathrm{L}$ of the medium (Trios), which was incubated as above.

Suspected $E$. coli isolates grown on the agar with ciprofloxacin were analyzed by MALDI-TOF MS (Biotyper Microflex, Bruker) to identify the species. Confirmed $E$. coli strains were reinoculated onto Mueller-Hinton blood agar (Trios) and tested using a microdilution method (Trios) for resistance to selected quinolone antibiotics - oxolinic acid, ofloxacin and ciprofloxacin. The plates with antibiotics were incubated aerobically for 24 hours at $37^{\circ} \mathrm{C}$ according to the 2014 EUCAST criteria (23). As quality controls, reference strains of E. coli (ATCC 25922; ATCC 35218) and Pseudomonas aeruginosa (ATCC 27853) were used. The results were assessed using clinical breakpoints. A total of 212 E. coli isolates were examined (126 environmental samples from poultry farms and 86 isolates from turkey cloacal swabs).

In the 86 E. coli isolates from turkey cloacal swabs, polymerase chain reaction (PCR) and sequencing methods were applied to detect the presence of PMQR genes. Total DNA was extracted by boiling. The obtained isolates were tested by PCR for the presence of the following PMQR genes: aac (6')-Ib-cr, qepA, qnrA, qnrB, $q n r C, q n r D, q n r S$, and $o q x A B$; the primers used were specified in studies by Jacoby et al. (24) and Literak et al. (25). 
Table 1. Resistance to quinolone antibiotics in E. coli isolates

\begin{tabular}{|l|c|c|c|c|}
\hline Tested antibiotics & Breakpoints & $\begin{array}{c}\text { Resistance of environmen- } \\
\text { tal E. coli } \\
(\mathrm{N}=126)\end{array}$ & $\begin{array}{c}\text { Resistance of turkey } \\
\text { E. coli } \\
(\mathrm{N}=86)\end{array}$ & $\begin{array}{c}\text { Total resistance of E. coli } \\
(\mathrm{N}=212)\end{array}$ \\
\hline Oxolinic acid & 8 & $86 \%$ & $54 \%$ & $73 \%$ \\
\hline Ofloxacin & 0.5 & $56 \%$ & $49 \%$ & $53 \%$ \\
\hline Ciprofloxacin & 0.5 & $61 \%$ & $45 \%$ & $55 \%$ \\
\hline
\end{tabular}

\section{RESULTS}

Resistance to individual quinolone antibiotics of the tested $E$. coli isolates obtained from poultry is summarized in Table 1 . The highest level of resistance (73\%) was found in oxolinic acid (the only first-generation quinolone). For fluoroquinolones (ofloxacin, ciprofloxacin), the resistance levels were nearly identical (53\% and $55 \%$, respectively).

When comparing resistance of isolates from both types of samples, a difference was apparent in case of oxolinic acid. Resistance to this antimicrobial was higher in $E$. coli isolates from the poultry house environment ( $86 \%$ ) than in isolates from turkey cloacal swabs (54\%). In fluoroquinolones, the resistance levels were approximately the same.

The presence of PMQR genes was tested in 86 E. coli isolates from turkey cloacal swabs. The genes were confirmed in 50 samples $(58 \%)$. The $q n r B$ and $q n r S$ genes were found in $16(19 \%)$ and $45(52 \%)$ samples, respectively. Both genes were confirmed in $11(13 \%)$ samples.

\section{DISCUSSION AND CONCLUSION}

Populations of animals, in particular poultry, are considered one of potential sources of multidrug-resistant bacteria threatening humans, including bacteria with plasmid-mediated resistance genes $(27,28)$.

The levels of resistance of $E$. coli strains isolated from poultry to quinolone antibiotics determined by the present study are consistent with those commonly seen in European countries. The resistance levels of our samples to quinolone antibiotics ranged from $53 \%$ to $73 \%$ and were thus similar to those reported in 2015 by Skočková et al. (15), who reported 55\% resistance to nalidixic acid and $38 \%$ to ciprofloxacin in poultry at retail in the Czech Republic. In European countries, resistance to ciprofloxacin in poultry was about 52\% in 2012 (16). The resistance of E. coli to this fluorinated quinolone was highest in Belgium (80\%) and lowest in Denmark (8\%). In the present study, $55 \%$ of tested strains were resistant to the antibiotic.

Data from both the present study and European countries were also consistent with those reported in a 4-year Polish study published by Wasyl et al. in 2013 (29). The authors investigated antibiotic resistance of $E$. coli strains in poultry, pigs and cattle and concluded that the highest levels of resistance to quinolone antibiotics were noted in poultry, with a mean resistance of $61 \%$ as compared to $10 \%$ in pigs and $3 \%$ in cattle. Resistance to ciprofloxacin in E. coli strains isolated from turkeys ranging from $22 \%$ to $61 \%$ were also demonstrated in a 2012 UK study by Gosling et al. (30). In lying hens in Belgium, the level of resistance to nalidixic acid was $38 \%$ (31).

According to the EARS-Net, the resistance of E. coli isolated from humans to fluoroquinolones reached $22 \%$ in the Czech Republic in 2013, dropping from $27 \%$ over a period of 4 years (17). These data correspond with those found in the University Hospital Olomouc (13-20\%; data not published).

The present study showed higher levels of plasmid-mediated resistance in $q n r B$ and $q n r S$ genes in E. coli strains isolated from poultry as compared with other European countries. The $q n r B$ and $q n r S$ genes were detected in $19 \%$ and $52 \%$ of the tested samples, respectively. In a 2011 study comprising 13 European countries (including the Czech Republic), Veldman et al. (18) determined plasmid-mediated resistance of E. coli and Salmonella enterica strains from animals, humans, foods and the environment between 1994 and 2009. The presence of PMQR genes in E. coli reported by the study is not consistent with the present results. Similar to our findings, the authors failed to confirm the presence of $q n r A$, $q n r D$ and $a a c\left(6^{\circ}\right)-1 b-c r$ genes but did find $q n r B(1 \%)$ and $q n r S$ $(15 \%)$ genes. However, the percentages were higher in the present study, namely $19 \%$ for $q n r B$ and $52 \%$ for $q n r S$.

In the UK study described by Gosling et al. (30) the presence of PMQR genes was confirmed in E. coli isolated from turkey but the rates were different. Whereas both the present study and the European study by Veldman et al. (18) showed higher frequency of the $q n r S$ gene, the UK study reported $q n r B$ and $q n r S$ genes in $4 \%$ and $2 \%$ of samples, respectively. The British authors also detected the aac (6 $\left.6^{\circ}\right)-1 b-c r$ gene in $1 \%$ of samples.

In 2012, qnr of the PMQR genes was confirmed by Husičková et al. (19) in clinical isolates obtained from University Hospital Olomouc patients. The rates were relatively high, namely $56 \%$ of qnrB-positive isolates of Klebsiella pneumoniae which were also ESBL-positive. This is in contrast with European studies showing generally lower percentages of $q n r$ genes in clinical isolates of ESBL-positive strains (4\% in Spain or France and $9 \%$ in Norway or Sweden), but higher levels of the $a a c\left(6^{\circ}\right)-1 b$ cr gene (16\% in Spain, 23\% in France and 52\% in Norway or Sweden) (20-22).

The high levels of resistance determined by both phenotyping and genotyping methods and reported in the present study confirm the fact that the use of fluoroquinolones in poultry should be closely monitored. These antimicrobials should be used as little as possible as drugs with limited indications.

The presence of PMQR genes in both animals and humans is suggestive of potential horizontal transfer of the resistance genes between strains $(18,20-22)$.

Potential transfer of resistant bacteria from poultry to humans was studied by van den Bogaard et al. in the Netherlands in 2001 
(32). The authors used pulsed-field gel electrophoresis to confirm clonal relationship of $E$. coli strains from poultry and poultry farmers. Similarly, two 2010 Iceland studies suggested that poultry, poultry meat or even poultry feeds could be potential sources of quinolone-resistant bacteria for humans, as documented close genetic relationship between resistant $E$. coli isolates from meat and one farm worker $(33,34)$.

In a group of 212 Escherichia coli isolates obtained from poultry, resistance to oxolinic acid, ofloxacin and ciprofloxacin was detected in $73 \%, 53 \%$ and $55 \%$ of the isolates. Higher levels of resistance were observed in environmental isolates (poultry houses) as compared with those from turkey cloacal swabs. The resistance to quinolones was significantly higher in E. coli isolated from poultry as compared with human isolates obtained in the same region. In $58 \%$ of the tested strains from animals, plasmidmediated quinolone resistance genes were present. The $q n r B$ and $q n r S$ resistance genes were detected in $19 \%(16 / 86)$ and $52 \%$ $(45 / 86)$ of the samples. Both genes were simultaneously present in $13 \%(11 / 86)$ of the samples.

\section{Acknowledgement}

Supported by the Czech Ministry of Health (IGA MZ ČR NT 14398)

\section{Conflict of Interests}

None declared

\section{REFERENCES}

1. Koláčková I, Házová K, Skočková A, Karpíšková R. Occurrence of Shiga toxigenic Escherichia coli strains in pigs and cattle at slaughterhouses in the Czech Republic in 2013. Klin Mikrobiol Infekc Lek. 2014 Jun;20(2):36-9. (In Czech.)

2. Bagheri M, Ghanbarpour R, Alizade H. Shiga toxin and beta-lactamases genes in Escherichia coli phylotypes isolated from carcasses of broiler chickens slaughtered in Iran. Int J Food Microbiol. 2014 May 2;177:1620.

3. Hopkins KL, Davies RH, Threlfall EJ. Mechanisms of quinolone resistance in Escherichia coli and Salmonella: recent developments. Int J Antimicrob Agents. 2005 May;25(5):358-73.

4. Kroemer S, El Garch F, Galland D, Petit JL, Woehrle F, Boulouis HJ. Antibiotic susceptibility of bacteria isolated from infections in cats and dogs throughout Europe (2002-2009). Comp Immunol Microbiol Infect Dis. 2014 Mar;37(2):97-108.

5. Institute for State Control of Veterinary Biologicals and Medicines. Veterinary drugs with restricted indication (2014 update) [Internet]. Prague: Institute for State Control of Veterinary Biologicals and Medicines; 2014 [cited 2017 Mar 20]. Available from: http://www.uskvbl.cz/cs/component/ search/indika $\% \mathrm{C} 4 \% 8 \mathrm{Dn} \% \mathrm{C} 3 \% \mathrm{AD} \% 20$ omezen $\% \mathrm{C} 3 \% \mathrm{AD} /$ ?ordering $=\&$ searchphrase=all. (In Czech.)

6. Kolář M, Bardoň J, Sauer P, Kesselová M, Čekanová L, Vágnerová I, et al. Fluoroquinolone-resistant Escherichia coli and Proteus mirabilis in poultry of Middle Moravia, Czech Republic. Act Vet Brno. 2005;74(2):249-53.

7. Martinez M, McDermott P, Walker R. Pharmacology of the fluoroquinolones: a perspective for the use in domestic animals. Vet J. 2006 Jul;172(1):10-28.

8. Robicsek A, Jacoby GA, Hooper DC. The worldwide emergence of plasmid-mediated quinolone resistance. Lancet Infect Dis. 2006 Oct;6(10):629-40.

9. Kučera J. Fluoroquinolones and canine urinary tract infections. Veterinářství. 2006;56(2):71-6. (In Czech.)

10. Fluit AC, Visser MR, Schmitz FJ. Molecular detection of antimicrobial resistance. Clin Microbiol Rev. 2001 Oct;14(4):836-71.

11. Hooper DC. Emerging mechanisms of fluoroquinolone resistance. Emerg Infect Dis. 2001 Mar-Apr;7(2):337-41.

12. Briales A, Rodríguez-Martínez JM, Velasco C, Díaz de Alba P, Domínguez-Herrera J, Pachón J, et al. In vitro effect of qnrA1, qnrB1, and qnrS1 genes on fluoroquinolone activity against isogenic Escherichia coli isolates with mutations in gyrA and parC. Antimicrob Agents Chemother. 2011 Mar;55(3):1266-9.

13. Cerquetti M, García-Fernández A, Giufrè M, Fortini D, Accogli M, Graziani C, et al. First report of plasmid-mediated quinolone resistance determinant qnrS1 in an Escherichia coli strain of animal origin in Italy. Antimicrob Agents Chemother. 2009 Jul;53(7):3112-4.

14. Ma J, Zeng Z, Chen Z, Xu X, Wang X, Deng Y, et al. High prevalence of plasmid-mediated quinolone resistance determinants qnr, aac $\left(6^{\prime}\right)$-Ibcr, and qepA among ceftiofur-resistant Enterobacteriaceae isolates from companion and food-producing animals. Antimicrob Agents Chemother. 2009 Feb;53(2):519-24.

15. Skočková A, Koláčková I, Bogdanovičová K, Karpíšková R. Characteristic and antimicrobial resistance in Escherichia coli from retail meats purchased in the Czech Republic. Food Control. 2015 Jan;47:401-6.

16. European Food Safety Authority; European Centre for Disease Prevention and Control. The European Union Summary Report on antimicrobial resistance in zoonotic and indicator bacteria from humans, animals and food in 2012. EFSA J. 2014;12(3):3590. doi:10.2903/j.efsa.2014.3590.

17. European Centre for Disease Prevention and Control. European Antimicrobial Resistance Surveillance Network (EARS-Net) [Internet]. Stockholm: ECDC [cited 2017 Mar 20]. Available from: http://ecdc. europa.eu/en/healthtopics/antimicrobial-resistance-and-consumption/ antimicrobial_resistance/EARS-Net/Pages/EARS-Net.aspx.

18. Veldman K, Cavaco LM, Mevius D, Battisti A, Franco A, Botteldoorn $\mathrm{N}$, et al. International collaborative study on the occurrence of plasmidmediated quinolone resistance in Salmonella enterica and Escherichia coli isolated from animals, humans, food and the environment in 13 European countries. J Antimicrob Chemother. 2011 Jun;66(6):1278-86.

19. Husičková V, Chromá M, Htoutou Sedláková M, Kolář M. Presence of qnr genes in ESBL-positive isolates of Klebsiella pneumoniae. Klin Mikrobiol Inf Lek. 2012;18(3):60-4. (In Czech.)

20. Karah N, Poirel L, Bengtsson S, Sundqvist M, Kahlmeter G, Nordmann $\mathrm{P}$, et al.; Norwegian Study Group on PMQR. Plasmid-mediated quinolone resistance determinants qnr and aac(6')-Ib-cr in Escherichia coli and Klebsiella spp. from Norway and Sweden. Diagn Microbiol Infect Dis. 2010 Apr;66(4):425-31.

21. Crémet L, Caroff N, Dauvergne S, Reynaud A, Lepelletier D, Corvec $\mathrm{S}$. Prevalence of plasmid-mediated quinolone resistance determinants in ESBL Enterobacteriaceae clinical isolates over a 1-year period in a French hospital. Pathol Biol (Paris). 2011 Jun;59(3):151-6.

22. Briales A, Rodríguez-Martínez JM, Velasco C, de Alba PD, RodríguezBaño J, Martínez-Martínez L, et al. Prevalence of plasmid-mediated quinolone resistance determinants qnr and aac(6')-Ib-cr in Escherichia coli and Klebsiella pneumoniae producing extended-spectrum $\beta$-lactamases in Spain. Int J Antimicrob Agents. 2012 May;39(5):431-4.

23. The European Committee on Antimicrobial Susceptibility Testing. Breakpoint tables for interpretation of MICs and zone diameters. Version 4.0 [Internet]. EUCAST; 2014 [cited 2017 Mar 20]. Available from: https:// asmsig.files.wordpress.com/2014/11/breakpoint_table_v_4-01-2014.pdf.

24. Jacoby GA, Griffin CM, Hooper DC. Citrobacter spp. as a source of qnrB Alleles. Antimicrob Agents Chemother. 2011 Nov;55(11):4979-84.

25. Literak I, Micudova M, Tausova D, Cizek A, Dolejska M, Papousek I, et al. Plasmid-mediated quinolone resistance genes in fecal bacteria from rooks commonly wintering throughout Europe. Microb Drug Resist. 2012 Dec;18(6):567-73.

26. Bardoň J, Kolář M, Karpíšková R, Hricová K. Prevalence of thermotolerant Campylobacter spp. in broilers at retail in the Czech Republic and their antibiotic resistance. Food Control. 2011 Feb 22(2):328-32.

27. Egervärn M, Börjesson S, Byfors S, Finn M, Kaipe C, Englund S, et al. Escherichia coli with extended-spectrum beta-lactamases or transferable AmpC beta-lactamases and Salmonella on meat imported into Sweden. Int J Food Microbiol. 2014 Feb 3;171:8-14.

28. Leverstein-van Hall MA, Dierikx CM, Cohen Stuart J, Voets GM, van den Munckhof MP, van Essen-Zandbergen A, et al.; National ESBL surveillance group. Dutch patients, retail chicken meat and poultry share the same ESBL genes, plasmids and strains. Clin Microbiol Infect. 2011 Jun;17(6):873-80.

29. Wasyl D, Hoszowski A, Zając M, Szulowski K. Antimicrobial resistance in commensal Escherichia coli isolated from animals at slaughter. Front Microbiol. 2013 Aug 5;4:221. doi: 10.3389/fmicb.2013.00221.

30. Gosling RJ, Clouting CS, Randall LP, Horton RA, Davies RH. Ciprofloxacin resistance in E. coli isolated from turkeys in Great Britain. Avian Pathol. 2012;41(1):83-9. 
31. Oosterik LH, Peeters L, Mutuku I, Goddeeris BM, Butaye P. Susceptibility of avian pathogenic Escherichia coli from laying hens in Belgium to antibiotics and disinfectants and integron prevalence. Avian Dis. 2014 Jun;58(2):271-8.

32. van den Bogaard AE, London N, Driessen C, Stobberingh EE. Antibiotic resistance of faecal Escherichia coli in poultry, poultry farmers and poultry slaughterers. J Antimicrob Chemother. 2001 Jun;47(6):763-71.

33. Thorsteinsdottir TR, Haraldsson G, Fridriksdottir V, Kristinsson KG, Gunnarsson E. Broiler chickens as source of human fluoroquinolone-resistant Escherichia coli, Iceland. Emerg Infect Dis. 2010 Jan;16(1):133-5.
34. Thorsteinsdottir TR, Haraldsson G, Fridriksdottir V, Kristinsson KG, Gunnarsson E. Prevalence and genetic relatedness of antimicrobial-resistant Escherichia coli isolated from animals, foods and humans in Iceland. Zoonoses Public Health. 2010 May;57(3):189-96.

Received March 3, 2015 Accepted in revised form March 20, 2017 